\title{
Reducing Agents Decrease the Oxidative Burst and Improve Clinical Outcomes in COPD Patients: A Randomised Controlled Trial on the Effects of Sulphurous Thermal Water Inhalation
}

\author{
Marco Contoli, ${ }^{1}$ Giulia Gnesini, ${ }^{1}$ Giacomo Forini, ${ }^{1}$ Brunilda Marku, ${ }^{1}$ \\ Alessia Pauletti, ${ }^{1}$ Anna Padovani, ${ }^{1}$ Paolo Casolari, ${ }^{1}$ Liliana Taurino, ${ }^{1}$ Andrea Ferraro, ${ }^{1}$ \\ Milva Chicca, ${ }^{2}$ Adalberto Ciaccia, ${ }^{1}$ Alberto Papi, ${ }^{1}$ and Silvano Pinamonti ${ }^{2}$ \\ ${ }^{1}$ Department of Medical Sciences, Research Centre on Asthma and COPD, University of Ferrara, Via Savonarola 9, 44121 Ferrara, Italy \\ ${ }^{2}$ Department of Life Science and Biotechnology, University of Ferrara, Via Savonarola 9, 44121 Ferrara, Italy
}

Correspondence should be addressed to Marco Contoli; ctm@unife.it

Received 24 August 2013; Accepted 1 October 2013

Academic Editors: A. De Roux, N. Scichilone, L. A. Stanciu, and F. Varoli

Copyright (C) 2013 Marco Contoli et al. This is an open access article distributed under the Creative Commons Attribution License, which permits unrestricted use, distribution, and reproduction in any medium, provided the original work is properly cited.

Background. Inhalation of thermal water with antioxidant properties is empirically used for COPD. Aims. To evaluate the effects of sulphurous thermal water (reducing agents) on airway oxidant stress and clinical outcomes in COPD. Methods. Forty moderate-to-severe COPD patients were randomly assigned to receive 12-day inhalation with sulphurous thermal water or isotonic saline. Patients were assessed for superoxide anion $\left(\mathrm{O}_{2}^{-}\right)$production in the exhaled breath condensate and clinical outcomes at recruitment, the day after the conclusion of the 12-day inhalation treatment, and one month after the end of the inhalation treatment. Results. Inhalation of reducing agents resulted in a significant reduction of $\mathrm{O}_{2}{ }^{-}$production in exhaled breath condensate of COPD patients at the end of the inhalatory treatment and at followup compared to baseline. A significant improvement in the COPD assessment test (CAT) questionnaire was shown one month after the end of the inhalatory treatment only in patients receiving sulphurous water. Conclusion. Thermal water inhalation produced an in vivo antioxidant effect and improvement in health status in COPD patients. Larger studies are required in order to evaluate whether inhalation of thermal water is able to modify relevant clinical outcomes of the disease (the study was registered at clinicaltrial.gov-identifier: NCT01664767).

\section{Introduction}

Chronic obstructive pulmonary disease (COPD) is a leading cause of morbidity and mortality worldwide and results in a substantial and increasing economic and social burden [1]. COPD is characterised by persistent airflow limitation that is usually progressive and that is associated with enhanced chronic inflammatory response of the airways and the lung to noxious particles or gases [1].

Oxidative stress is a key component of airway inflammation in COPD $[2,3]$. In particular, the reactive metabolites of oxygen, such as superoxide anion $\left(\mathrm{O}_{2}{ }^{-}\right)$and the hydroxyl radical, are unstable molecules that can trigger significant oxidative processes at the cellular level. Such molecules can induce remodelling of the extracellular matrix and create a protease-antiprotease imbalance, and can alter cellular respiration, cell proliferation, surfactant production, the airway epithelial repair process and the immune response of the lung $[2,4,5]$.

The regular use of antioxidant agents in COPD patients has been investigated in many long-term studies with conflicting results [6]. International guidelines report that the widespread of these agents cannot be recommended at present; that N-Acetyl-L-Cysteine (NAC) may have antioxidant effects; and that treatment with carbocisteine and NAC in COPD patients not receiving inhaled corticosteroids may reduce exacerbations [1].

The inhalation of thermal water with antioxidant properties is not considered to be a therapeutic option for COPD 
patients according to international guidelines [1]. However, the inhalation of thermal water has been used since the dawn of medicine to treat patients suffering from chronic disorders, including respiratory symptoms; such treatments are still used because they always have been. A "PubMed" search for the terms "COPD and thermal water inhalation" shows that there are only two placebo controlled studies focusing on the biological impact of thermal water inhalation on markers of airway inflammation in COPD patients $[7,8]$. In several European countries, such as Italy, the costs of thermal water inhalation treatment for patients with COPD are reimbursed by the National Health System. In the era of evidence-based medicine and of economical restraint/cutting of budgets, cost/benefit analyses must be considered seriously.

The possible benefit of inhalation of thermal water for the treatment of chronic respiratory disorders has been mainly related to its supposed mucolytic, anti-inflammatory, and antioxidant properties [9-11]. Hydrogen sulphide $\left(\mathrm{H}_{2} \mathrm{~S}\right)$ is a potent reducing agent that is present at high levels in sulphurous thermal waters and in lower concentrations in salt-bromide-iodine waters. Recently, we documented that treatment of bronchial epithelial cell lines with sulphurous thermal water before rhinovirus infection resulted in increased concentrations of the endogenous intracellular reducing agent GSH and in the inhibition of a rhinovirusinduced intracellular oxidant burst [12].

Based on these observations, we conducted a randomised controlled study to evaluate the effects of sulphurous thermal water (containing reducing agents) on airway oxidant stress, airway inflammation, and clinical outcomes in patients with COPD.

\section{Material and Methods}

2.1. Study Population. COPD patients were recruited at the outpatient clinic of the Respiratory Disease Section of the University of Ferrara, Italy.

The study population included 40 COPD patients, according to GOLD criteria [1]. We recruited patients aged $50-80$ years old with a postbronchodilator FEV1/FVC ratio $<70 \%$ and a postbronchodilator FEV1 ranging from $30 \%$ to $80 \%$ of that predicted (GOLD stages 2 and 3) [1]. Patients were enrolled into the study if they had been stable (i.e., free from exacerbations and/or requiring any changes in their treatment) for the previous 3 months. Patients with a clinical history or diagnosis of asthma were excluded from the study. During the study, patients continued to use their maintenance treatment. The study conformed to the Declaration of Helsinki, the local Institutional Ethics Committee approved the work, and informed written consent was obtained from each subject. The study was registered at clinicaltrial.gov (identifier: NCT01664767).

2.2. Study Design. This was a randomised, double-blinded, and controlled study that was designed to evaluate the effect of the inhalation of reducing agents (administered by inhalation of sulphurous thermal water) on airway oxidant stress and to evaluate the impact of sulphurous thermal water inhalation on clinical outcomes in COPD patients. Patients randomised to the study underwent home inhalation of sulphurous water (Acqua Breta, Terme di Riolo; Ravenna, Italy) or isotonic saline solution for 12 days. The treatment plan consisted of once daily inhalation of either sulphurous water or isotonic saline in 2 different formulations: (1) $500 \mathrm{~mL}$ warm inhalation, and after 20 minutes, (2) $5 \mathrm{~mL}$ conventional aerosolisation. This treatment plan mimics a standard onsite course of spa inhalation (warm inhalation followed by conventional aerosolisation). Sulphurous water from the springs of Riolo Terme, Ravenna (Italy) was bottled sterile in dark green glass bottles and was delivered to the Respiratory Section outpatient clinic at the University of Ferrara. Isotonic saline was bottled in similar dark green bottles. Bottle handling was performed by a person not involved in the study and who was also in charge of the randomisation procedures. Active treatment (sulphurous water) was indistinguishable from the isotonic saline (control). Twelve bottles containing sulphurous water or isotonic saline and the devices for the two inhalation procedures were delivered to the patients' homes. The investigator instructed the patients and taught them how to use the devices during the first visit. The chemical and physical characteristic of the sulphurous water and of the isotonic saline are reported in Table 1. The study consisted of three visits: recruitment (baseline), the day after the conclusion of the 12-day inhalation treatment (end of treatment), and one month after the end of the inhalation treatment (followup). At each visit, patients underwent a physical examination, lung function testing, and an assessment of their health status by the COPD Assessment Test (CAT) questionnaire. At each visit, exhaled breath condensate and sputum samples were also obtained.

2.3. Lung Function Test. Pulmonary function tests (Biomedin Spirometer, Padova, Italy) were performed according to published guidelines $[13,14]$.

2.4. CAT Questionnaire. The COPD Assessment Test (CAT) is an 8-item unidimensional measure of health status impairment in COPD. It was developed to be applicable worldwide and validated translations are available in a wide range of languages. In our study we used a validated Italian CAT version. The scores range from 0 to $40[15,16]$. A CAT score $>10$ is found in symptomatic patients [1].

2.5. Sputum Processing. Spontaneous or induced sputum was collected and analysed according to standardised procedures, as previously described [17]. Sputum plugs arising from the lower respiratory tract were selected for total sputum inflammatory cell counts [18].

2.6. Exhaled Breath Condensate Collection and Processing. Exhaled breath condensate (EBC) was collected during oral tidal breathing using a commercial condenser (Turbo Deccs 04, Italchil, Parma, Italy) according to previous studies [19, 20]. Briefly, the subjects were not allowed to eat or drink for at least $1 \mathrm{~h}$ before EBC collection. Patients breathed normally through a mouthpiece for $15 \mathrm{~min}$ and a 2-way 
TABLE 1: Physical and chemical characteristics of sulphurous water and isotonic saline.

\begin{tabular}{lcc}
\hline Parameters & Sulphurous water & Isotonic saline \\
\hline $\mathrm{pH}$ & 7.1 & $4.5-7.0$ \\
$\mathrm{Ca}_{2}{ }^{+} \mathrm{g} / \mathrm{L}$ & 0.251 & Absent \\
$\mathrm{Mg}_{2}{ }^{+} \mathrm{g} / \mathrm{L}$ & 0.091 & Absent \\
$\mathrm{NH}_{4}{ }^{+} \mathrm{g} / \mathrm{L}$ & 0.00075 & Absent \\
$\mathrm{HCO}_{3}{ }^{-} \mathrm{g} / \mathrm{L}$ & 0.523 & Absent \\
$\mathrm{SO}_{4}{ }^{-} \mathrm{g} / \mathrm{L}$ & 0.5 & Absent \\
$\mathrm{H}_{2} \mathrm{Sg} / \mathrm{L}$ & 3.83 & Absent \\
\hline
\end{tabular}

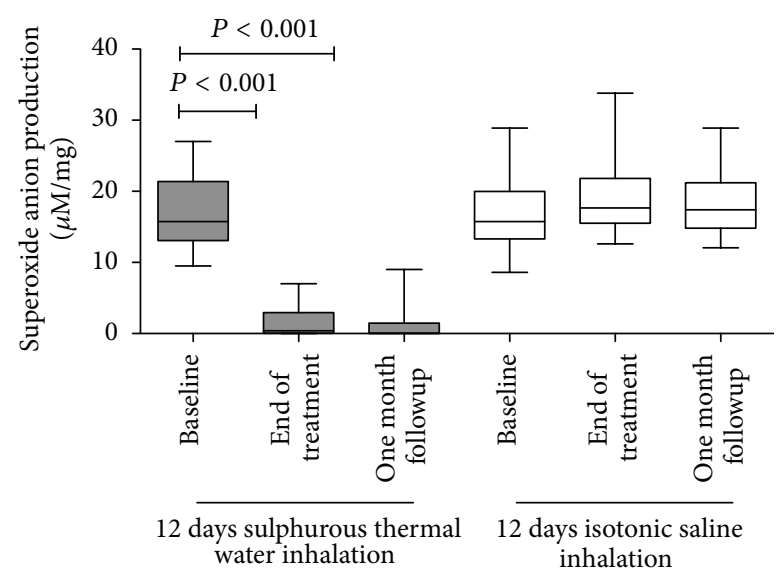

FIGURE 1: Superoxide anion production in COPD patients at the baseline, at the end of the inhalation treatment, and one month after the end of the treatment.

nonrebreathing valve that also served as a saliva trap. If the subjects felt saliva in their mouth, they were instructed to swallow it. The $50 \mathrm{~mL}$ Falcon collecting tubes were prefilled with $300 \mu \mathrm{L}$ of solution consisting of $5 \times 10^{-2} \mathrm{M}$ cytochrome $c$ from beef heart (Sigma), $5 \times 10^{-3} \mathrm{M}$ catalase, and Penicillin/Streptomycin $(0.1 \mathrm{U} / 0.1 \mu \mathrm{g})$, respectively, in each sample. The tubes connecting the mouthpiece to the collecting Falcon tubes were set to allow the patients to blow directly into the solution placed at the bottom of the $50 \mathrm{~mL}$ Falcon tubes. The harvested breath condensate was collected at $-10^{\circ} \mathrm{C}$, transferred to an Eppendorf tube on ice, and immediately tested for $\mathrm{O}_{2}{ }^{-}$levels. The levels of $\mathrm{O}_{2}{ }^{-}$were spectrophotometrically evaluated by xanthine oxidase (XO) cytochrome $c$ reduction kinetics, as previously described $[12,21]$. The kinetics assays were carried out in $1 \mathrm{~mL}$ quartz cuvettes at $37^{\circ} \mathrm{C}$ for $30 \mathrm{~min}$ in a Uvikon 860 (Kontron Instruments) spectrophotometer in the presence or absence of xanthine $(0.1 \mathrm{mM}$, Sigma). Absorbance readings were taken at $550 \mathrm{~nm}$ (peak of reduced cytochrome). Newly generated $\mathrm{O}_{2}{ }^{-}$was measured in each sample and data are expressed in micromolar concentrations. These measurements were based on the absorbance differences in the presence or absence of xanthine at the peak of the kinetic slope of cytochrome $c$ reduction [12]. The data were normalised per $\mathrm{mg}$ of protein as determined using a Bradford assay.

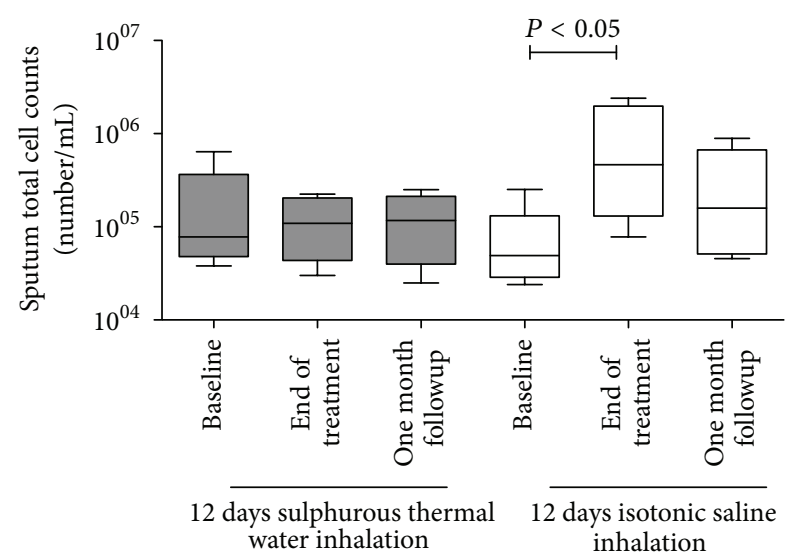

FIGURE 2: Total sputum cell counts in COPD patients at the baseline, at the end of the inhalation treatment, and one month after the end of the treatment.

2.7. Sample Size Calculation and Statistical Analysis. The aim of this study was to evaluate the effect of sulphurous thermal water inhalation on exhaled breath superoxide anion production. The procedures used in this study to detect superoxide anion production in exhaled breath condensate have previously been developed and internally optimised in our laboratory. A pilot analysis was conducted in stable moderate COPD patients and smokers with normal lung function to obtain reference baseline values. Based on our data, we estimated that 18 patients/group would be sufficient to detect a reduction in superoxide anion of $50 \%$. Comparisons within groups were evaluated by ANOVA, followed, when results were significant, by using Student $t$ tests or Mann-Whitney $U$ tests, as appropriate. Comparisons between groups were evaluated using a Kruskal-Wallis test, followed, when results were significant, by using Student $t$ tests or Mann-Whitney $U$ tests, as appropriate. $P$ values of 0.05 or less were considered to indicate statistical significance. GraphPad Prism 5.0 Software was used for the analysis.

\section{Results}

3.1. Study Population. Seventy-six consecutive COPD patients referred to the outpatient clinics of the Respiratory Section of the University of Ferrara were screened. Nineteen patients did not meet the inclusion criteria of the study, and seventeen patients did not choose to participate in the study. The inhalation procedures were well tolerated, and all of the patients who enrolled completed the study. No COPD exacerbations were observed during the course of the study treatments. At baseline, no difference was found in the demographic, clinical, and functional characteristics of the patients treated with isotonic saline or sulphurous thermal water (Table 2).

3.2. Effect of Sulphurous Thermal Water Inhalation on the Airway Oxidative Burst. At baseline, a significant amount of $\mathrm{O}_{2}{ }^{-}$ production was observed in the exhaled breath condensate of 
TABLE 2: Characteristics of the study population at the baseline.

\begin{tabular}{|c|c|c|c|c|}
\hline & Study population & $\begin{array}{l}\text { Patients treated with } \\
\text { inhaled sulphurous water }\end{array}$ & $\begin{array}{l}\text { Patients treated with } \\
\text { inhaled isotonic saline }\end{array}$ & $P$ value ${ }^{*}$ \\
\hline$n$ & 40 & 20 & 20 & \\
\hline Age & $69.9 \pm 1.0$ & $69.3 \pm 1.5$ & $70.4 \pm 1.4$ & ns \\
\hline Sex (male/female) & 29/11 & $14 / 6$ & $15 / 5$ & ns \\
\hline \multicolumn{5}{|l|}{ Smoking habit } \\
\hline Pack/years & $39.7 \pm 2.2$ & $38.5 \pm 3.2$ & $41.1 \pm 2.2$ & ns \\
\hline Current smokers $(n)$ & & 1 & 1 & \\
\hline Exsmokers $(n)$ & & 19 & 19 & \\
\hline Nonsmokers $(n)$ & & 0 & 0 & \\
\hline Prebronchodilator FEV1 (litre) & $1.38 \pm 0.06$ & $1.41 \pm 0.09$ & $1.35 \pm 0.08$ & ns \\
\hline Prebronchodilator FEV1 (\%) & $54.3 \pm 1.8$ & $54.9 \pm 2.6$ & $53.6 \pm 2.5$ & ns \\
\hline Postbronchodilator FEV1 (litre) & $1.48 \pm 0.07$ & $1.52 \pm 0.10$ & $1.44 \pm 0.08$ & ns \\
\hline Postbronchodilator FEV1 (\%) & $58.1 \pm 1.8$ & $58.9 \pm 2.7$ & $57.4 \pm 2.6$ & ns \\
\hline Reversibility to bronchodilator (litre) & $0.10 \pm 0.01$ & $0.11 \pm 0.01$ & $0.09 \pm 0.01$ & ns \\
\hline Reversibility to bronchodilator (\%) & $6.7 \pm 0.4$ & $6.8 \pm 0.5$ & $6.6 \pm 0.7$ & ns \\
\hline Residual volume (\%) & $154.4 \pm 7.4$ & $149.5 \pm 10.7$ & $156.5 \pm 10.3$ & ns \\
\hline Use of long acting antimuscarin (\%) & 11 & 5 & 6 & ns \\
\hline Use of long acting $\beta 2$-agonist (\%) & 38 & 18 & 18 & ns \\
\hline Beclomethasone (BDP) equivalent daily dose $(\mu \mathrm{g})$ & $1545 \pm 110$ & $1571 \pm 159$ & $1520 \pm 157$ & ns \\
\hline Use of inhaled corticosteroids $(n)$ & 29 & 15 & 14 & ns \\
\hline CAT score & $13.4 \pm 0.9$ & $13.3 \pm 1.2$ & $13.6 \pm 1.4$ & $\mathrm{~ns}$ \\
\hline
\end{tabular}

${ }^{*}$ Patients treated with inhaled sulphurous water versus patients treated with inhaled isotonic saline.

TABLE 3: Inflammatory cell counts in the sputum of COPD patients.

\begin{tabular}{lcccccc}
\hline & \multicolumn{3}{c}{ Sulphurous water inhalation } & \multicolumn{3}{c}{ Isotonic saline inhalation } \\
& Baseline & End of treatment & One month followup & Baseline & End of treatment & One month followup \\
\hline Macrophages (\%) & $25 \pm 11$ & $26 \pm 16$ & $19.3 \pm 13$ & $19.5 \pm 8.6$ & $17.9 \pm 12.8$ & $20.1 \pm 9.8$ \\
Neutrophils (\%) & $72.8 \pm 10.0$ & $74 \pm 16$ & $78.9 \pm 12$ & $79.9 \pm 4.6$ & $82.1 \pm 14.3$ & $78.8 \pm 11.8$ \\
Eosinophils (\%) & $1.2 \pm 0.6$ & 0 & $1.1 \pm 0.4$ & $0.6 \pm 0.3$ & 0 & $0.5 \pm 0.2$ \\
Lymphocytes (\%) & $0.3 \pm 0.1$ & 0 & $0.7 \pm 0.3$ & 0 & 0 & $0.6 \pm 0.3$ \\
\hline
\end{tabular}

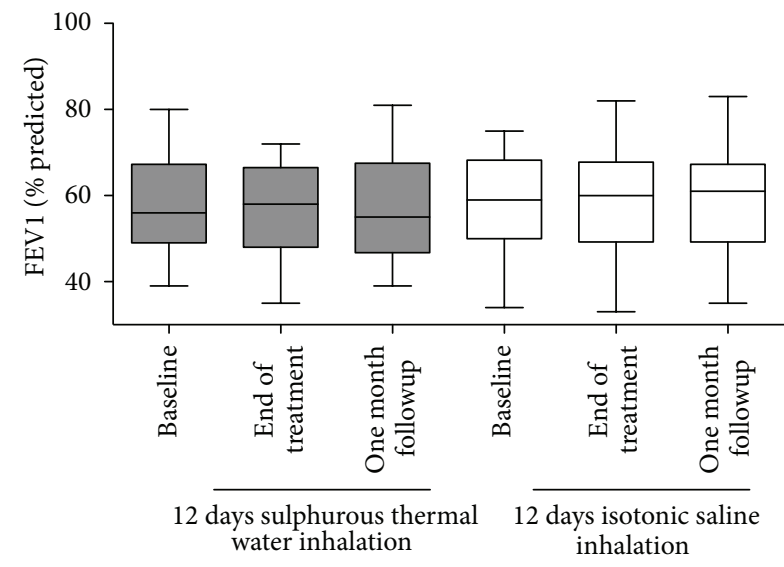

(a)

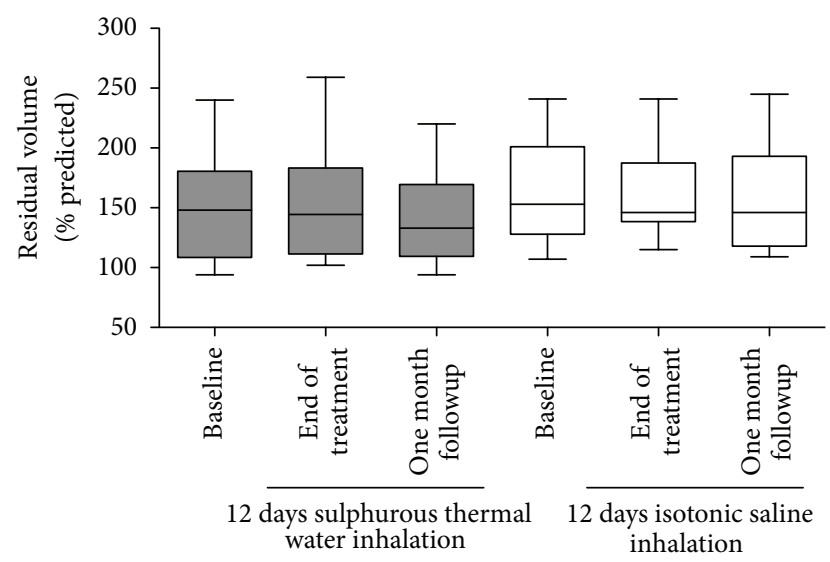

(b)

FIGURE 3: Lung function parameters (postbronchodilator FEV1 and residual volume) in COPD patients at the baseline, at the end of the inhalation treatment, and one month after the end of the treatment. 


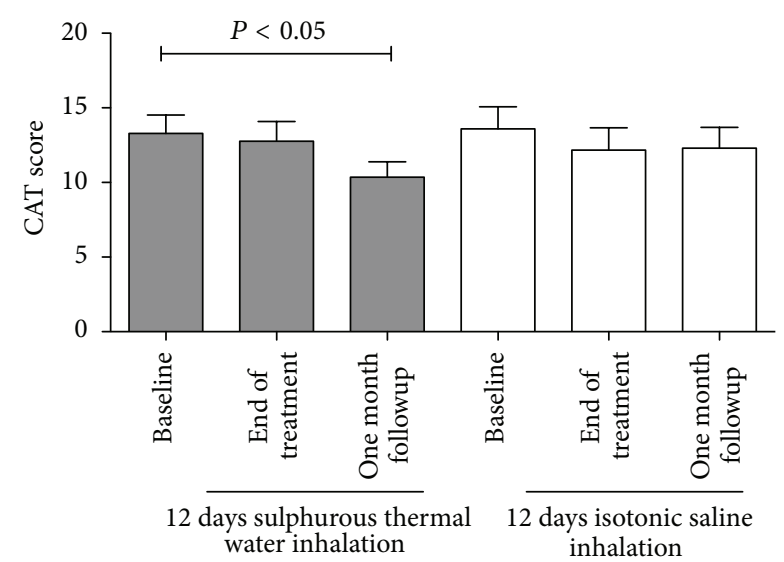

Figure 4: COPD Assessment Test (CAT) questionnaire in COPD patients at the baseline, at the end of the inhalation treatment, and one month after the end of the treatment.

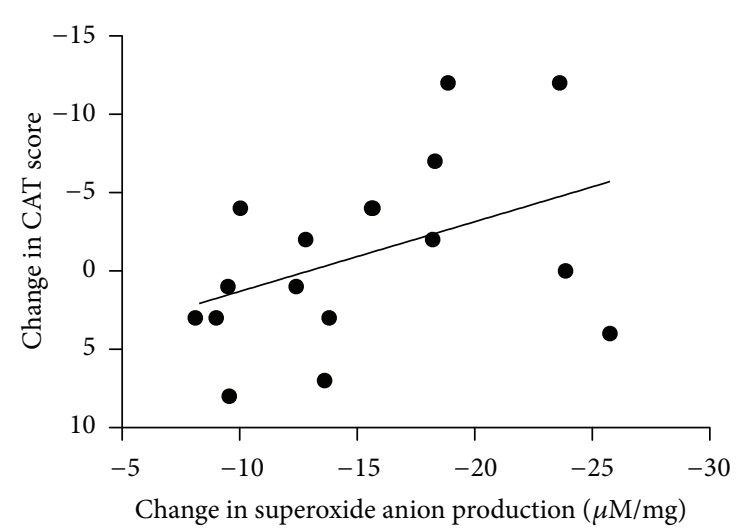

FIgURE 5: Correlation between changes in COPD Assessment Test (CAT) questionnaire score and superoxide anion production in exhaled breath condensate of COPD treated with sulphurous thermal water at one month after the end of the inhalatory treatment compared to baseline.

the COPD patients after the addition of xanthine. This indicates the presence of xanthine oxidase in the exhaled breath condensate. $\mathrm{O}_{2}{ }^{-}$production was virtually undetectable at the end of the 12-day inhalation treatment with sulphurous thermal water $(P<0.001) . \mathrm{O}_{2}{ }^{-}$production was inhibited by the 12-day inhalation treatment with sulphurous thermal water irrespective of the disease severity or corticosteroid treatment (data not shown). The inhibition of $\mathrm{O}_{2}{ }^{-}$production persisted for one month after the completion of the 12-day inhalation treatment with sulphurous thermal water $(P<$ $0.001-$ Figure 1 ). The COPD patients who received isotonic saline inhalation showed no change in their $\mathrm{O}_{2}{ }^{-}$production at the time points examined (Figure 1).

\subsection{Effect of Sulphurous Thermal Water Inhalation on Sputum} Total Inflammatory Cell Counts. At the end of the treatment and at the one-month follow-up visit, there was no difference from the baseline in the total sputum cell counts (Figure 2) in the group of COPD patients receiving sulphurous thermal water inhalation. At the end of the inhalation treatment, we observed a significant increase over the baseline in the total sputum cell counts in the group of patients receiving isotonic saline inhalation $(P<0.05)$. There was no difference in the differential inflammatory cell counts at any of the time points examined in either group (Table 3 ).

3.4. Effect of Sulphurous Thermal Water Inhalation on Lung Function. Lung function parameters did not change significantly in either group at the end of the treatment and at the one month followup when they were compared with the baseline measurements (Figure 3 ).

3.5. Effect of the Sulphurous Thermal Water Inhalation Treatment on the Symptomatic Impact of the Disease. We observed a significant reduction in the CAT score (approximately 2.5 units) one month after the end of the sulphurous thermal water inhalation treatment compared with the score at the baseline $(P<0.05)$. We observed no differences in CAT scores in the group of patients receiving the isotonic saline as a control (Figure 4). In patients treated with sulphurous thermal water, a positive correlation was found between the improvement in CAT score and the reduction of $\mathrm{O}_{2}{ }^{-}$ production in the exhaled breath condensate that just missed the statistical significance $(P=0.08, r=0.42-$ Figure 5$)$. In line with the current clinical use of the thermal water inhalation in COPD patients, no major adverse events were documented.

\section{Discussion}

In this study, we found that a course of sulphurous thermal water treatment reduced oxidative stress in the airways of moderate to severe COPD patients and improved the patients' reported symptomatic impact of the disease.

Despite the wide use of thermal water inhalation treatment for chronic respiratory disorders (including COPD) the evidence supporting a clinically measurable improvement after treatment is rather weak. To date, only two placebocontrolled studies have specifically addressed this issue. Pellegrini et al. showed that a 12-day thermal water inhalation treatment resulted in a small but significant reduction in sputum neutrophilic inflammation and a short term improvement in quality of life at the end of the treatment; however, there was no short term effect on exercise capacity (measured by 6-minute walking test) or on lung function parameters [22]. Guarnieri et al. failed to document a significant reduction in neutrophil chemoattractant leukotriene B4 (LTB4) in exhaled breath condensate after a 12-day thermal water inhalation treatment but showed a significant change in exhaled breath condensate $\mathrm{pH}$ measurements, suggesting that thermal water inhalation can modify the biological substrate of the disease [7].

The importance of an oxidant/antioxidant imbalance in the pathogenesis of COPD is well established [2]. Thus, therapeutic strategies targeting oxidative stress with pharmacological antioxidants or designed to increase the endogenous levels of antioxidants are expected to be beneficial as an 
additional tool that may be used in the treatment of COPD patients. Potentially such an intervention could increase the corticosteroid sensitivity of COPD patients [23-25]. Under physiologic conditions, oxidant generation in the airways has both endogenous and exogenous sources. One of the more relevant pro-oxidative pathways of the respiratory system is the xanthine dehydrogenase/xanthine oxidase system that leads to the new generation of superoxide anion through the catabolism of the purine base xanthine [26, 27]. Increased xanthine oxidase activity has been documented in the bronchoalveolar lavage of COPD patients when compared with that of healthy subject $[21,28,29]$. It has also been shown that the treatment of COPD patients with oral allopurinol, an inhibitor of xanthine oxidase, resulted in a significant reduction in airway reactive nitrogen species [29], indicating that this intervention may be useful in reducing the inflammatory and airway oxidative burst in chronic obstructive pulmonary disease. Proteolytic and nonproteolytic pathways mediate the activation of the xanthine dehydrogenase/xanthine oxidase system [26, 27]. In particular, among nonproteolytic pathways, it has been documented that intracellular depletion of reducing agents, such as GSH, leads to xanthine dehydrogenase/xanthine oxidase system activation $[30,31]$. We have previously reported that in vitro stimulation of bronchial epithelial cells with sulphurous thermal water results in increased intracellular GSH levels [12]. In this study, we found a significant in vivo reduction of xanthine-induced superoxide anion production following a course of reducing agents that were delivered by sulphurous thermal water inhalation. Taken together these data suggest that the inhalation of sulphurous thermal water results in increased intracellular antioxidant levels that are able to modulate or inhibit the activation of the xanthine dehydrogenase/xanthine oxidase system, thereby decreasing the airway oxidative burst in COPD patients. Thus, modulation of xanthine oxidase may represent a therapeutic option for decreasing oxidative stress in the lungs of COPD patients. Consistent with a previous study [22], we observed an increased number of total sputum cells after the 12-day course of saline inhalation treatment as a control. The increased recovery of cells in the induced sputum that we observed after the treatment is in line with the observations made in COPD patients whose inhalation of isotonic or hypertonic solutions administered by nebulisation induces increases in airway secretions that can be expectorated [32]. The increased recovery did not occur after 12-day sulphurous water inhalation, suggesting that this inhalation does not affect airway secretion and/or inflammation. Interestingly we also documented that (i) the antioxidant effect persisted for up to one month after the end of the inhalation treatment period; and (ii) the antioxidant effect was paralleled by a significant improvement in the patient's reported symptomatic impact of COPD, supporting an interplay between the modulation of the oxidative burst and an improvement in clinical outcomes in these patients.

In line with previous findings [22], we failed to document any improvement in lung function following the thermal water inhalation treatment in COPD patients. Pellegrini et al. previously reported a short term improvement in the quality of life of COPD patients following the thermal water inhalation treatment [22]. We now extend these findings by reporting a significant improvement in symptoms that persist for one month after the end of the inhalation treatment.

Although we cannot exclude that some patients might have perceived the thermal vapour characteristics, it is unlikely that this affected the result of the study since the improvement in the symptomatic impact of the disease was not observed immediately after the end of the inhalation treatment but it appeared one month after its completion. This reinforced the reliability of the conclusion. However, the link between thermal water inhalation treatment and an improvement in the patient's reported quality of life in COPD patients remains largely unexplored.

In conclusion, thermal water inhalation treatment is a safe procedure leading to in vivo antioxidant effects in COPD patients. Thermal water inhalation treatment in COPD patients results in positive clinical effects in self-reported quality of life that persists one month after the end of the treatment. Larger studies are needed to confirm the positive clinical findings of thermal water inhalation treatment in COPD patients. Even more importantly, studies with a longer follow-up time frame up are required to evaluate whether inhalation of thermal water is able to modify relevant clinical outcomes of the disease.

\section{Conflict of Interests}

The authors declare that there is no conflict of interests regarding the publication of this paper.

\section{Authors' Contribution}

Alberto Papi and Silvano Pinamonti contributed equally to this study.

\section{Acknowledgment}

This study was supported by a research grant from Terme di Riolo Bagni, Riolo Terme, Ravenna, Italy.

\section{References}

[1] Global Initiative for Chronic Obstructive Lung Disease (GOLD), Global Strategy for the Diagnosis, Management and Prevention of Chronic Obstructive Pulmonary Disease: NHLBI/ WHO Workshop Report, Publication no. 2701:1-108, National Institutes of Health, National Heart, Lung and Blood Institute, Bethesda, Md, USA, 2001, http://www.goldcopd.org/.

[2] S. Psarras, G. Caramori, M. Contoli, N. Papadopoulos, and A. Papi, "Oxidants in asthma and in chronic obstructive pulmonary disease (COPD)," Current Pharmaceutical Design, vol. 11, no. 16, pp. 2053-2062, 2005.

[3] P. J. Barnes, “Chronic obstructive pulmonary disease," The New England Journal of Medicine, vol. 343, no. 4, pp. 269-280, 2000.

[4] J. T. Hancock, R. Desikan, and S. J. Neill, "Role of reactive oxygen species in cell signalling pathways," Biochemical Society Transactions, vol. 29, no. 2, pp. 345-350, 2001.

[5] S. P. Faux, T. Tai, D. Thorne, Y. Xu, D. Breheny, and M. Gaca, "The role of oxidative stress in the biological responses of 
lung epithelial cells to cigarette smoke," Biomarkers, vol. 14, supplement 1, pp. 90-96, 2009.

[6] G. Hillas, S. Nikolakopoulou, S. Hussain, and T. Vassilakopoulos, "Antioxidants and mucolytics in COPD management: when (if ever) and in whom?" Current Drug Targets, vol. 14, no. 2, pp. 225-234, 2013.

[7] G. Guarnieri, S. Ferrazzoni, M. C. Scarpa, A. Lalli, and P. Maestrelli, "Effects of inhalation of thermal water on exhaled breath condensate in chronic obstructive pulmonary disease," Respiration, vol. 79, no. 3, pp. 216-221, 2010.

[8] M. Pellegrini, D. Fanin, Y. Nowicki et al., "Effect of inhalation of thermal water on airway inflammation in chronic obstructive pulmonary disease," Respiratory Medicine, vol. 99, no. 6, pp. 748-754, 2005.

[9] P. C. Braga, G. Sambataro, M. Dal Sasso, M. Culici, M. Alfieri, and G. Nappi, "Antioxidant effect of sulphurous thermal water on human neutrophil bursts: chemiluminescence evaluation," Respiration, vol. 75, no. 2, pp. 193-201, 2008.

[10] S. Valitutti, F. Castellino, and P. Musiani, "Effect of sulfurous (thermal) water on $\mathrm{T}$ lymphocyte proliferative response," Annals of Allergy, vol. 65, no. 6, pp. 463-468, 1990.

[11] P. C. Braga, M. Dal Sasso, M. Culici et al., "Effects of sulphurous water on human neutrophil elastase release," Therapeutic Advances in Respiratory Disease, vol. 4, no. 6, pp. 333-340, 2010.

[12] A. Papi, M. Contoli, P. Gasparini et al., "Role of xanthine oxidase activation and reduced glutathione depletion in rhinovirus induction of inflammation in respiratory epithelial cells," The Journal of Biological Chemistry, vol. 283, no. 42, pp. 2859528606, 2008.

[13] M. R. Miller, J. Hankinson, V. Brusasco et al., "Standardisation of spirometry," European Respiratory Journal, vol. 26, no. 2, pp. 319-338, 2005.

[14] J. Wanger, J. L. Clausen, A. Coates et al., "Standardisation of the measurement of lung volumes," European Respiratory Journal, vol. 26, no. 3, pp. 511-522, 2005.

[15] P. W. Jones, G. Harding, P. Berry, I. Wiklund, W.-H. Chen, and N. Kline Leidy, "Development and first validation of the COPD Assessment Test," European Respiratory Journal, vol. 34, no. 3, pp. 648-654, 2009.

[16] P. W. Jones, G. Brusselle, R. W. Dal Negro et al., "Properties of the COPD assessment test in a cross-sectional European study," European Respiratory Journal, vol. 38, no. 1, pp. 29-35, 2011.

[17] L. M. Fabbri, M. Romagnoli, L. Corbetta et al., "Differences in airway inflammation in patients with fixed airflow obstruction due to asthma or chronic obstructive pulmonary disease," American Journal of Respiratory and Critical Care Medicine, vol. 167, no. 3, pp. 418-424, 2003.

[18] A. Efthimiadis, A. Spanevello, Q. Hamid et al., "Methods of sputum processing for cell counts, immunocytochemistry and in situ hybridisation," European Respiratory Journal, Supplement, vol. 20, no. 37, pp. 19s-23s, 2002.

[19] M. Goldoni, A. Caglieri, R. Andreoli et al., "Influence of condensation temperature on selected exhaled breath parameters," BMC Pulmonary Medicine, vol. 5, article 10, 2005.

[20] A. Caglieri, M. Goldoni, O. Acampa et al., "The effect of inhaled chromium on different exhaled breath condensate biomarkers among chrome-plating workers," Environmental Health Perspectives, vol. 114, no. 4, pp. 542-546, 2006.

[21] S. Pinamonti, M. Muzzoli, M. C. Chicca et al., "Xanthine oxidase activity in bronchoalveolar lavage fluid from patients with chronic obstructive pulmonary disease," Free Radical Biology and Medicine, vol. 21, no. 2, pp. 147-155, 1996.

[22] M. Pellegrini, D. Fanin, Y. Nowicki et al., "Effect of inhalation of thermal water on airway inflammation in chronic obstructive pulmonary disease," Respiratory Medicine, vol. 99, no. 6, pp. 748-754, 2005.

[23] K. Ito, K. F. Chung, and I. M. Adcock, "Update on glucocorticoid action and resistance," Journal of Allergy and Clinical Immunology, vol. 117, no. 3, pp. 522-543, 2006.

[24] K. Ito, S. Lim, G. Caramori, K. F. Chung, P. J. Barnes, and I. M. Adcock, "Cigarette smoking reduces histone deacetylase 2 expression, enhances cytokine expression, and inhibits glucocorticoid actions in alveolar macrophages," The FASEB Journal, vol. 15, no. 6, pp. 1110-1112, 2001.

[25] J. A. Marwick, G. Caramori, C. S. Stevenson et al., "Inhibition of PI3K $\delta$ restores glucocorticoid function in smoking-induced airway inflammation in mice," American Journal of Respiratory and Critical Care Medicine, vol. 179, no. 7, pp. 542-548, 2009.

[26] R. Hille and T. Nishino, "Flavoprotein structure and mechanism. 4. Xanthine oxidase and xanthine dehydrogenase," The FASEB Journal, vol. 9, no. 11, pp. 995-1003, 1995.

[27] C. Enroth, B. T. Eger, K. Okamoto, T. Nishino, T. Nishino, and E. F. Pai, "Crystal structures of bovine milk xanthine dehydrogenase and xanthine oxidase: structure-based mechanism of conversion," Proceedings of the National Academy of Sciences of the United States of America, vol. 97, no. 20, pp. 10723-10728, 2000.

[28] S. Pinamonti, M. Leis, A. Barbieri et al., "Detection of xanthine oxidase activity products by EPR and HPLC in bronchoalveolar lavage fluid from patients with chronic obstructive pulmonary disease," Free Radical Biology and Medicine, vol. 25, no. 7, pp. 771-779, 1998.

[29] M. Ichinose, H. Sugiura, S. Yamagata et al., "Xanthine oxidase inhibition reduces reactive nitrogen species production in COPD airways," European Respiratory Journal, vol. 22, no. 3, pp. 457-461, 2003.

[30] P. M. Hassoun, F. S. Yu, J. J. Zulueta, A. C. White, and J. J. Lanzillo, "Effect of nitric oxide and cell redox status on the regulation of endothelial cell xanthine dehydrogenase," American Journal of Physiology_Lung Cellular and Molecular Physiology, vol. 268, no. 5, pp. L809-L817, 1995.

[31] M. M. Lee, F. H. Y. Green, S. Schürch et al., "Comparison of inhibitory effects of oxygen radicals and calf serum protein on surfactant activity," Molecular and Cellular Biochemistry, vol. 259, no. 1-2, pp. 15-22, 2004.

[32] C. Taube, O. Holz, M. Mücke, R. A. Jorres, and H. Magnussen, "Airway response to inhaled hypertonic saline in patients with moderate to severe chronic obstructive pulmonary disease," American Journal of Respiratory and Critical Care Medicine, vol. 164 , no. 10, pp. 1810-1815, 2001. 


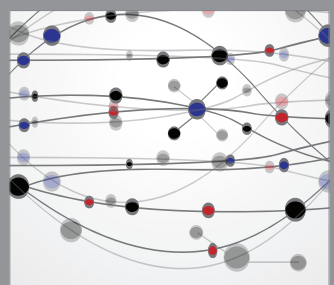

The Scientific World Journal
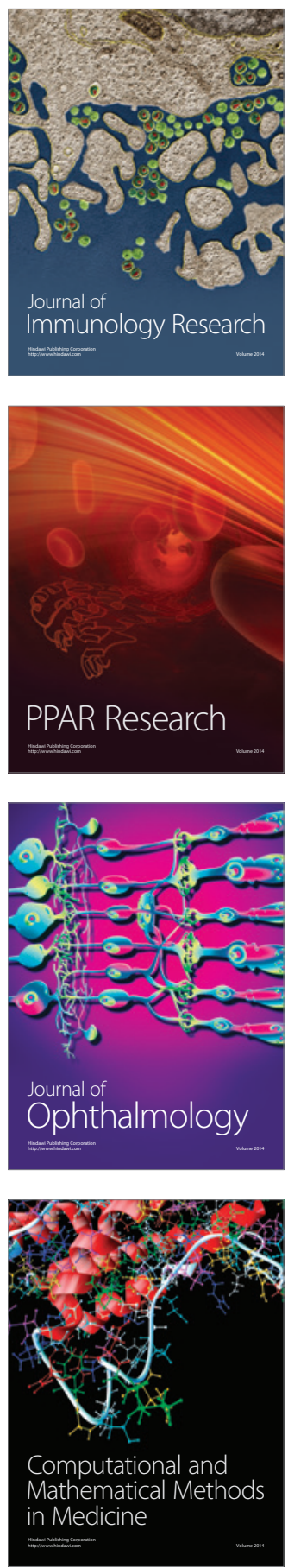

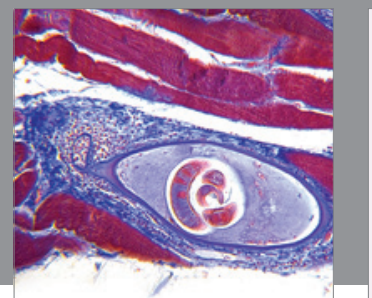

Gastroenterology

Research and Practice
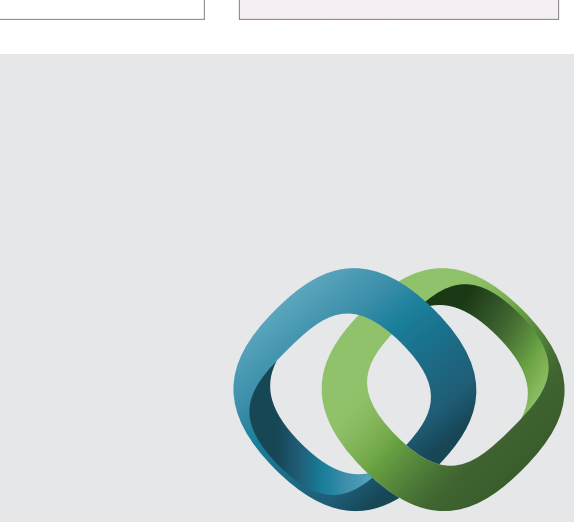

\section{Hindawi}

Submit your manuscripts at

http://www.hindawi.com
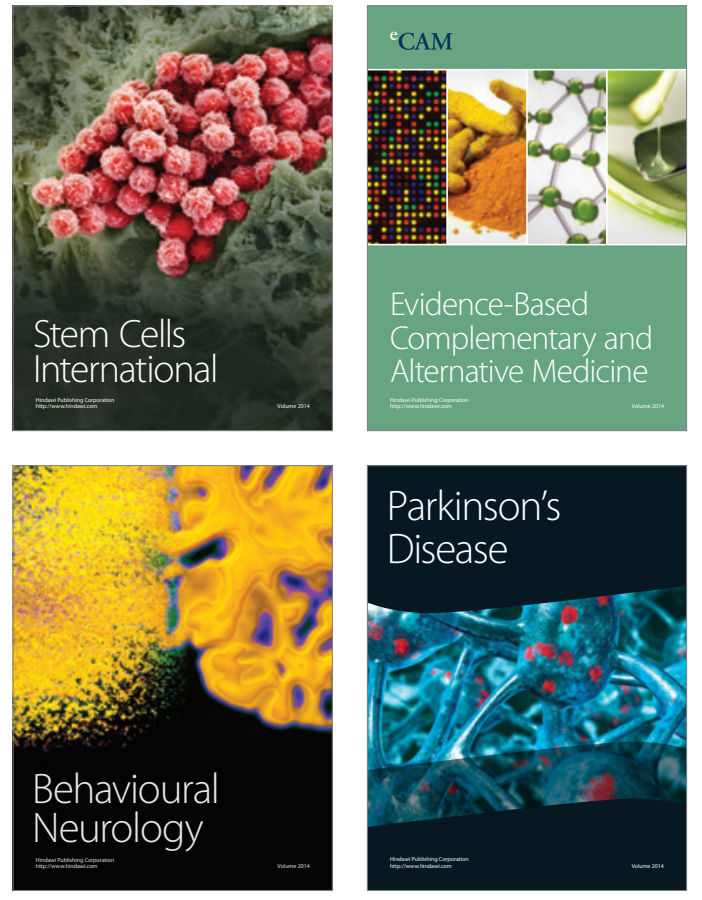
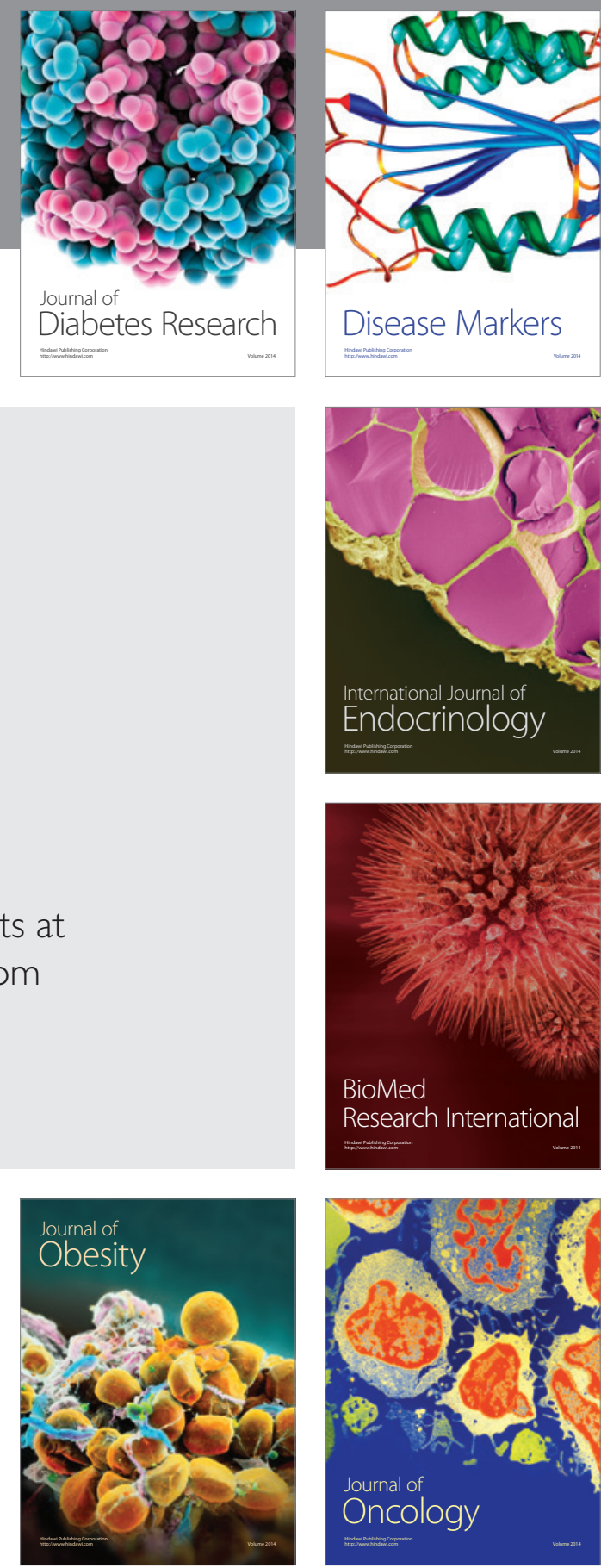

Disease Markers
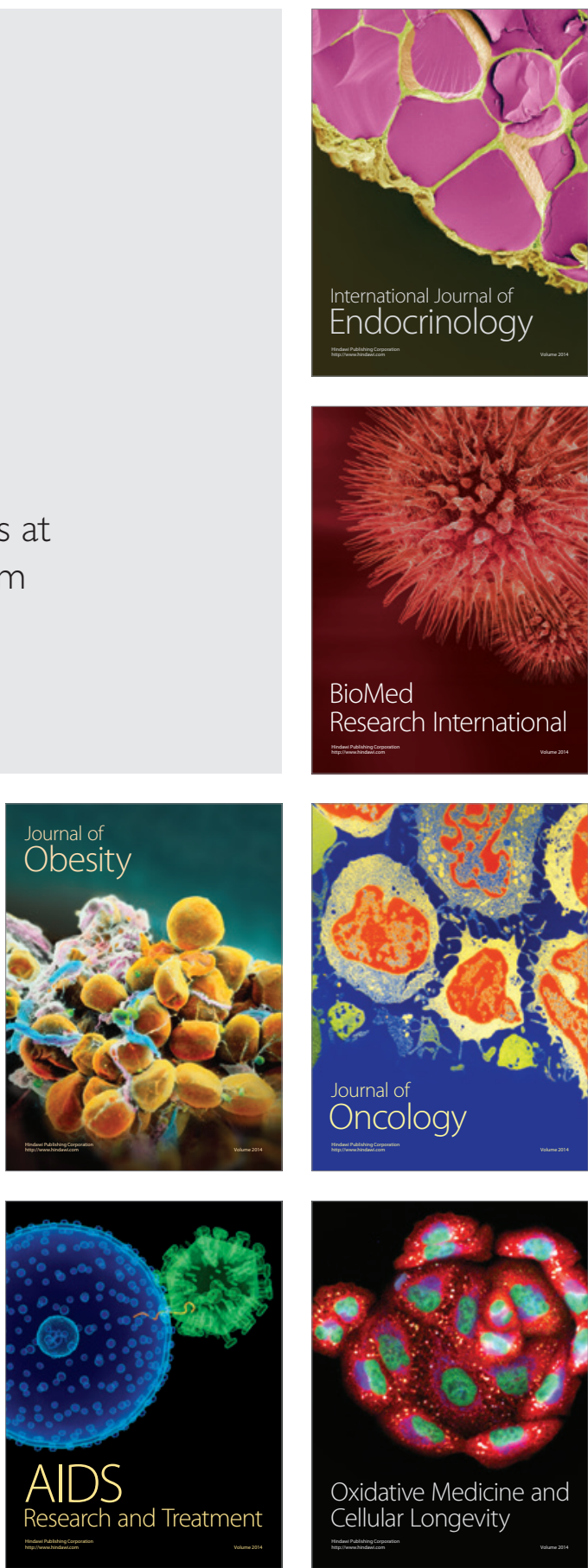